\title{
Endoscopic sigmoidorectal reanastomosis using a dual endoscope technique: rendezvous single-balloon enteroscopy and endoscopic ultrasound
}

While therapeutic endoscopic ultrasound (EUS) has shown promising results as a new modality to create EUS-guided gastroenterostomy using a lumen-apposing metal stent (LAMS), little data exist on its use as a rendezvous technique. We present a case of endoscopic reanastomosis using rendezvous single-balloon enteroscopy and EUS in a patient with complete sigmoid obstruction.

A 70-year-old woman was admitted to our department for treatment of a benign sigmoid colon obstruction. In the past, she had undergone surgical treatment for pelvic organ prolapse. The procedure was complicated by mesh migration and rectal necrosis requiring several surgical interventions, including an anterior resection of the rectum with surgical colostomy formation. Because of massive postoperative adhesions and limited abdominal access, the patient was referred for potential endoscopic treatment.

The rendezvous technique under fluoroscopic and endosonographic guidance was employed ( $\triangleright$ Video 1 ). The singleballoon enteroscope (Olympus, Japan) was advanced through the colostomy to the last part of the sigmoid colon while the echoendoscope (Pentax Medical, France; Hitachi Aloka ultrasound systems, Japan) was advanced through the anus into the rectal stump ( $\mathbf{F i g . 1}$ ). Then, about $200 \mathrm{ml}$ saline was injected into the rest of sigmoid through the single-balloon enteroscope. This allowed visualization of the fluid collection by EUS, and the optimal position was confirmed ( Fig.2). When the distance between the walls of the rectum and sigmoid was below $10 \mathrm{~mm}$, a $15-\mathrm{mm}$ Axios self-expandable metal stent was implanted ( $\vee$ Video 1 ). The implantation was performed under EUS and fluoroscopy guidance ( $\triangleright$ Fig. 3, $\triangleright$ Fig. 4). The lumen of the implanted stent was dilated with a balIoon (CRE RX biliary balloon dilatation catheter, Boston Scientific, USA). Four weeks later the stent was removed with

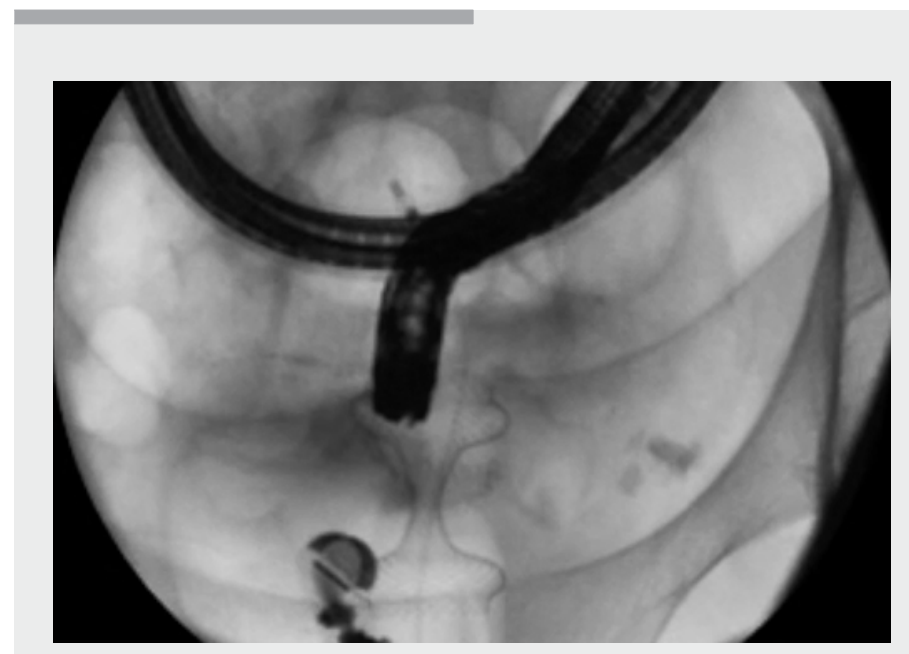

Video 1 Endoscopic sigmoidorectal reanastomosis using a dual endoscope technique: rendezvous single-balloon enteroscopy and endoscopic ultrasound.

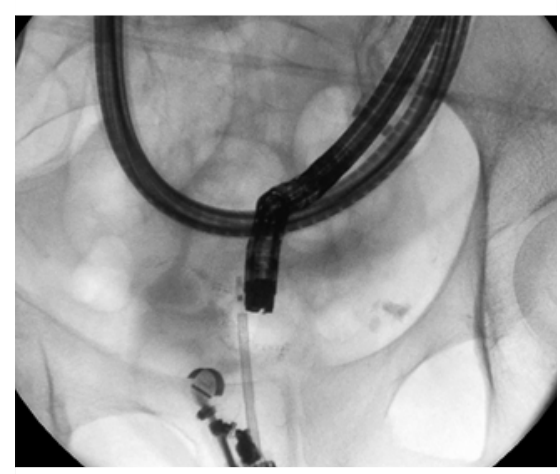

Fig. 1 Rendezvous technique: the single-balloon enteroscope advanced through the colostomy to the last part of the sigmoid colon and the echoendoscope advanced through the anus into the rectal stump.

a visible lumen of the restored gastrointestinal tract. After 3 days the colostomy was closed. During the 1 year of followup, no obstruction was observed and the function of the gastrointestinal tract was normal. In control endoscopies, the anastomosis was observed with a stable diameter of $20 \mathrm{~mm}$.

This case is interesting for several reasons. First, we show how simultaneous

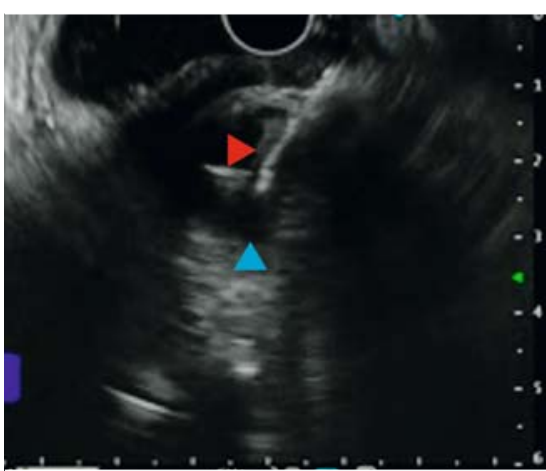

- Fig. 2 Saline injection to create a fluid collection (blue arrow) for optimal visualization of the procedure site. The needle of the Axios stent system is visible (red arrow).

utilization of two advanced endoscopic methods allows "roadmapping" of a complex intervention. Second, by filling the proximal sigmoid just above the stenosis, a practical puncture "cyst" was created to be accessed by endoscopic ultrasound. And, finally, easy placement of a metal stent was achieved using the rendezvous method. 


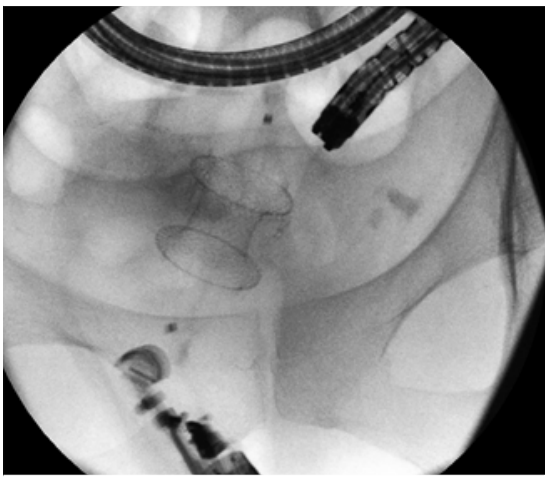

- Fig. 3 Placement of the Axios stent under fluoroscopic guidance.

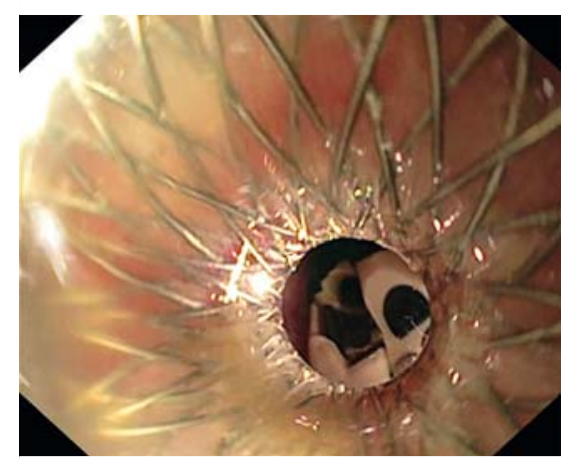

- Fig.4 Echoendoscope visible from the rectum through the lumen of the Axios stent.

Based on current literature, EUS-guided procedures are associated with a lower risk of adverse events, shortened length of hospital stay, and lower general cost compared to surgical techniques. However, further studies are required to con- firm their safety and long-term efficacy in the field of gastrointestinal tract restoration [1 - 3].

Endoscopy_UCTN_Code_TTT_1AQ_2AF

\section{Competing interests}

The authors declare that they have no conflict of interest.

The authors

\section{Sławomir Kozieł', Katarzyna Kozłowska-}

Petriczko², Katarzyna M. Pawlak ${ }^{3}$, Jan

Petriczko ${ }^{4}$, Anna Wiechowska-Kozłowska ${ }^{3}$

1 Department of General, Transplant and Liver Surgery, Medical University of Warsaw, Warsaw, Poland

2 Department of Gastroenterology and Internal Medicine, SPWSZ Hospital, Szczecin, Poland

3 Department of Gastroenterology, Hospital of the Ministry of Internal Affairs in Szczecin, Poland

4 Department of Plastic, Endocrine and General Surgery, Pomeranian Medical University, Szczecin, Poland

\section{Corresponding author}

\section{Katarzyna Monika Pawlak, MD, PhD}

Department of Gastroenterology, Hospital of the Ministry of Internal Affairs in Szczecin, Jagiellońska 44 st, 70-382 Szczecin, Poland Fax: +48-914-329501

pawlakatarzyna@gmail.com

\section{References}

[1] Guoxin W, Xiang L. Endoscopic ultrasoundguided gastroenterostomy: a promising alternative to surgery. J Transl Med 2019; 7: 93-99

[2] Jain D, Chhoda A, Sharma A et al. De-novo gastrointestinal anastomosis with lumen apposing metal stent. Clin Endosc 2018; 5 : 439-449

[3] Iqbal U, Khara HS, Hu Y et al. EUS-guided gastroenterostomy for the management of gastric outlet obstruction: a systematic review and meta-analysis. Endosc Ultrasound 2020; 9: 16-23

\section{Bibliography}

Endoscopy 2021; 53: E257-E258

DOI 10.1055/a-1247-4503

ISSN 0013-726X

published online 23.9.2020

(c) 2020. Thieme. All rights reserved.

Georg Thieme Verlag KG, Rüdigerstraße 14, 70469 Stuttgart, Germany

\section{ENDOSCOPY E-VIDEOS \\ https:/|eref.thieme.de/e-videos}

口回 Endoscopy E-Videos is a free

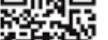
access online section, reporting on interesting cases and new

techniques in gastroenterological endoscopy. All papers include a high quality video and all contributions are freely accessible online.

This section has its own submission website at https://mc.manuscriptcentral.com/e-videos 